\title{
PROCEDIMENTO DE RIVES/STOPPA MODIFICADO ROBÔ-ASSISTIDO PARA CORREÇÃO DE HERNIAS VENTRAIS DA LINHA MÉDIA
}

\author{
Modified robot assisted Rives/Stoppa videosurgery for midline ventral hernia repair \\ Ricardo Zugaib ABDALLA, Rodrigo Biscuola GARCIA, Rafael Izar Domingues da COSTA, \\ Claudio Renato Penteado de LUCA, Beatrice Martinez Zugaib ABDALLA
}

Trabalho realizado no Hospital Sírio Libanês, São Paulo, SP, Brasil.

DESCRITORES - Hérnia ventral. Robótica. Parede abdominal. Hérnia umbilical.
RESUMO - Racional - Os defeitos da linha média podem ser congênitos ou adquiridos. Os procedimentos convencionais para correção desse defeito geralmente envolvem grandes incisões, com grandes descolamentos de pele e tecido celular subcutâneo. O uso da videocirurgia para a correção desses defeitos, ainda é controverso. Objetivos - Realizar descrição inédita na literatura, mostrando a experiência inicial do uso da robótica nas reconstruções de linha média, associando a cirurgia minimamente invasiva à técnicas consagradas como Rives/Stoppa e separação de componentes. Métodos - Foram operados cinco pacientes no mesmo hospital, pela mesma equipe, usando o sistema robótico da Vinci S. Resultados - Foram três mulheres e dois homens, sem mortalidade na amostra. Duas pacientes foram reoperadas com hérnia pelo tunel entre os músculos retos do abdomen e aponeurose posterior, com fechamento dos mesmos na reoperação. Conclusões - O procedimento robótico para reconstrução da linha média mostrou-se factível e esteticamente aceitável. Tem a vantagem de seguir os princípios tradicionais aventados para a parede abdominal através de via minimamente invasiva.

\section{Correspondência: \\ Ricardo Zugaib Abdalla, \\ e-mail: ricardo.abdalla@hsl.org.br}

Fonte de financiamento: não há

Conflito de interesses: não há

Recebido para publicação:

Aceito para publicação:

HEADINGS - Ventral hernia. Robotics. Abdominal wall. Umbilical hernia.
ABSTRACT- Background -The weakness of the linea alba can be caused by congenital and aquired factors. The conventional procedure to correct these imperfections generally involve large incisions with big detachments of the skin and subcutaneous tissue. The use of videosurgery for the repair of these weaknesses is still controversy. Aim - To describe a new procedure using robotics in the repair of the linea alba, associating minimally invasive tecniques by Rives/Stoppa and component separation tecniques. Methods - Five patients undergone surgery in the same hospital, the same operating team and using the Da Vinci S. robotics equipment. Results Three women and two men undergone surgery, with no mortality. Two of these patients were re-operated due a recurrent hernia between muscle and posterior sheath that was closed in the re-access. Conclusions - The robotic procedure in the reconstruction of the linea alba showed itself feasible and aesthetically acceptable. Also, in advantage, the procedure follows the traditional principals reputable by experts of the abdominal wall trough minimally invasive surgery.

\section{INTRODUÇÃO}

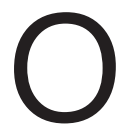
$s$ defeitos da linha média podem ser congênitos ou adquiridos. As hérnias congênitas, epigástricas, estão presentes em 3-5\% da população $0^{5}$. Alguns estudos mais recentes reportam incidência de $0,7 \% 8$. As adquiridas ocorrem de $3-20 \%$ das laparotomias medianas, com risco duplicado quando houve infecção do sítio cirúrgico ${ }^{3}$. Tais defeitos podem estar associados a diástase dos músculos retos do abdome acima da linha arqueada da aponeurose posterior desses músculos. É comum em obesos, pneumopatas, fumantes, idosos, desnutridos, pacientes com abdome flácido decorrente de má postura e pós-gestação ${ }^{8,9,14}$.

Os procedimentos convencionais para correção desse defeito da linha média geralmente envolvem grandes incisões, com grandes descolamentos de pele e tecido celular subcutâneo, uso de retalhos e plicaturas para 
aproximação da linha media. Estas necessidades potencializam o trauma cirúrgico, complicações e dor pós-operatória, morbidades passíveis de serem evitadas. Atualmente, o conceito de separação de componentes para reconstrução da parede anterior e linha média tem exigido dissecções por tecidos sadios que não participam diretamente da causa do defeito.

O uso da videocirurgia para a correção desses defeitos ainda é controverso ${ }^{7}$ e, por isso, tem-se realizado principalmente nos serviços onde é praticada por especialistas bem treinados. Mais limitado e controverso ainda é o uso da robótica em cirurgia da parede abdominal por ser um procedimento de uso recente na cirurgia geral.

No Brasil, o acesso aos equipamentos e aos materiais (grampeadores e telas) utilizados para esse fim ainda é muito restrito. Até o momento, não há um padrão para a correção desse problema ${ }^{10}$. Melhor resultado - medido pela recidiva em 10 anos - é alcançado quando se empregam próteses (telas) com estatísticas indicando recidiva em $63 \%$ sem tela, contra $10 \%$ com tela ${ }^{1,13}$.

A partir do ano 2000, começaram os trabalhos comparativos $^{2}$, randomizados e as discussões foram intensificadas nos encontros internacionais de estudiosos em hérnia7. Ainda assim, não está estabelecida indicação precisa para o método videocirúrgico. A videocirurgia tem sido escolhida, preferencialmente, para corrigir hérnias com diâmetro anelar maior do que $3 \mathrm{~cm}$ ou com mais de um defeito ${ }^{12}$ , quando as recidivas são múltiplas e nos pacientes obesos ou fumantes. O racional de seu uso é de ser correção sem tensão e que obrigatoriamente utiliza tela. É importante lembrar que muitos desses defeitos são entendidos no momento da operação, quando somente se reconhece a multiplicidade do defeito no decorrer da ampla dissecção dos tecidos, além da área acometida ${ }^{17}$.

Pela videocirurgia, é possível estadiar o defeito e planejar a sua correção, posicionando-se a tela dentro da cavidade peritoneal. Com isso, cria-se um anteparo à passagem do conteúdo herniário, apoiado ao redor do anel, sobre tecido sadio, resistente e onde a tela terá apoio para ser incorporada.

Considerando-se as diversas apresentações da doença herniária, a melhor posição do reparo com tela é que ela fique antes do peritônio parietal e por trás da musculatura abdominal, independente da via de acesso $0^{8,9}$. Na linha média, deve-se pensar em usar a aponeurose posterior dos músculos retos do abdome para a função de proteção da cavidade peritoneal. Com o desenvolvimento das telas compostas, ou de materiais que permitem o contato com as alças intestinais sem causar aderências firmes e/ou fístulas, a busca desse espaço deixa de ser uma obrigação e passa a depender da viabilidade técnica ou anatômica para ser alcançada.

O orifício herniário fica coberto pela tela, dando condições ao organismo de fechar progressivamente o defeito à frente do anteparo. As hérnias com anel menor do que $3 \mathrm{~cm}$ de diâmetro podem ser corrigidas por via anterior (aberta), sem a colocação de próteses ${ }^{9,13}$. A dissecção, nesses casos, é relativamente restrita e a tensão resultante, pequena.

O uso de próteses sintéticas com biomateriais combinados ou não, é um dos poucos consensos em literatura acerca desse procedimento, que permitiu diminuir os índices de recidiva de $54 \%$ para $10 \%$ ou menos 8,10 .

Além da indicação clínica, a videocirurgia traz vantagens inerentes ao método: menor tempo de hospitalização e de recuperação pós-operatória (imediata e tardia), menores índices de infecção do sítio cirúrgico, incisões menores, menor agressão cirúrgica e menos dor $r^{6,7,10,11}$. Especificamente na hérnia incisional e diástase dos músculos retos do abdome, evita o descolamento do tecido subcutâneo, a exposição e a manipulação dos músculos, a colocação de drenos, o uso de próteses extensas, solução de continuidade com a prótese e, finalmente, evita o uso de curativos restritivos com sequelas próprias de sua manutenção por tempo mais prolongado10,17. O inventário da cavidade permite a identificação de herniações que poderiam passar despercebidas por outra via. Por esse método, é possível proceder à lise de aderências de uma maneira eficaz e detalhada, criando um espaço ao redor dos limites do anel herniário com exposição da parede sadia, na qual será apoiada a maior superfície da tela ${ }^{6}$.

O objetivo desta publicação é realizar uma descrição inédita na literatura, mostrando a experiência inicial do uso da robótica nas reconstruções de linha média, usando a cirurgia minimamente invasiva em técnicas consagradas, como Rives/ Stoppa e separação de componentes.

\section{MÉTODO}

Foram operados cinco pacientes no Hospital Sírio-Libanês entre novembro de 2009 e abril de 2012. Praticou-se o protocolo cirúrgico descrito a seguir.

O paciente era posicionado em decúbito dorsal horizontal, com os membros superiores estendidos ao lado do corpo, os membros inferiores semi-fletidos e afastados entre si, permitindo o posicionamento adequado do braço robótico que sustenta a óptica com movimentação livre sobre o púbis. O cateterismo vesical era necessário nos defeitos do abdome inferior. Nas hérnias da linha mediana, o cirurgião começava à direita do paciente, posicionando o robô pelo ombro esquerdo do paciente.

Através de incisão suprapúbica de $1 \mathrm{~cm}$ com passagem de balão dilatador, era criado um amplo espaço de trabalho em compartimento pré-peritoneal, interessando regiões direita e esquerda inguinais da parede anterior, parede lateral, parede posterior até 
os limites dos músculos psoas direito e esquerdo, rebatendo-se o saco peritoneal em direção cranial e dorsal.

Após retirada do balão, era realizada passagem de óptica de $30^{\circ}$, para reconhecimento da linha arqueada da aponeurose dos músculos retos do abdome direito e esquerdo. Realizava-se dissecção do espaço retromuscular do músculo reto do abdome e progressão da dissecção como túnel retromuscular, até acima da cicatriz umbilical. Era realizado reconhecimento da prega umbilical medial e abertura da aponeurose posterior do músculo reto do abdome neste ponto, com tesoura, apontando para o sentido cranial e progressão da abertura pelo túnel retromuscular dissecado. Neste momento, pela dificuldade de se manter o espaço préperitoneal acima da cicatriz umbilical, era penetrada a cavidade, realizando-se o pneumoperitônio para afastar os órgãos intracavitários da parede anterior e permitir dissecção segura até a borda inferior da última costela do gradil torácico.

Com fio mono filamentar longo, fazia-se uma sutura na extremidade cranial das bordas das aponeuroses dissecadas, em direção podálica, aproximando-as e aos músculos retos, em conjunto, recriando uma parede em sua porção posterior. À frente da aponeurose posterior, em espaço retromuscular, colocava-se uma tela de $15 \mathrm{~cm}$ de largura por quantos centímetros fossem necessários até a linha arqueada, ou um pouco abaixo, fixando a tela com selante de fibrina em toda sua superfície.

Após a revisão da cavidade e da hemostasia, o pneumoperitônio era desfeito lentamente e todo o instrumental era retirado, sob visão direta. Caso existisse alguma abertura na aponeurose, igual ou maior do que $1 \mathrm{~cm}$ e que poderia ficar desprotegida pela prótese, ela era suturada.

\section{RESULTADOS}

Foram operados cinco pacientes através desta técnica. Todos apresentavam uma ou mais hérnias na linha media, incluindo umbilical, acompanhadas de diástase de músculos reto-abdominais. A amostra era composta de três mulheres e dois homens. A idade variou entre 35 e 68 anos.

Todos os pacientes tiveram boa aceitação de dieta líquida no pós- operatório imediato. Três tiveram alta hospitalar no segundo dia do pós-operatório e dois no primeiro.

Não houve mortalidade. Houve duas reoperações (primeira e quinta paciente operadas) por quadro sub-oclusivo intestinal. Nas duas o achado cirúrgico foi de herniação de intestino delgado entre a tela e aponeurose posterior dos músculos retos do abdomen. Foi realizada laparoscopia exploradora, retirada das alças e fechamento da linha semilunar nos dois casos. No primeiro caso a reabordagem foi cinco dias após a operação e no segundo caso seis dias após.

Todos os pacientes operados apresentaram melhora nítida do abaulamento na linha média e reaproximação das bordas mediais dos músculos retos do abdomen no exame físico e de imagem. Na última paciente desta série foi relizada aproximação das bordas médias da aponeurose posterior - do mesmo modo que na operação aberta -, refazendo-se a linha média. Esta manobra trouxe melhora ainda maior do abaulamento em relação aos pacientes anteriores.

\section{DISCUSSÃO}

O procedimento acima descrito consiste na realização do procedimento de Rives/Stoppa modificado com o acesso robótico. Tem como princípio aproximar os músculos retos do abdome entre si, reconstruindose a linha média conforme a tendência mundial de reconstrução funcional da parede abdominal nas herniorrafias $24,8,16$.

O sistema robótico permite sutura das bordas aponeuróticas com força e tensão apropriados, em movimentos curtos nos pequenos espaços próprios da situação. Esta manobra é possibilitada pela articulação dos punhos das pinças. Da mesma forma a extensão dos instrumentos permite chegar ao epigástrio através de portais inseridos no abdome inferior.

A dissecção da aponeurose posterior do músculo reto-abdominal mostra-se praticamente impossível através da via laparoscópica tradicional, com uso de pinças retas associado à elevação da parede abdominal pelo pneumoperitôneo ${ }^{6}$.

Teoricamente, esse método poderá ser de primeira escolha em qualquer defeito da parede abdominal e uma alternativa para os procedimentos combinados, que necessitem de esclarecimento diagnóstico mais detalhado, além dos exames de imagem não invasivos, ou mesmo de operações concomitantes (colecistectomia, por exemplo). Tem a vantagem de associar princípios da cirurgia plástica para correção da diástase dos músculos retos abdominais a um acesso minimamente invasivo, resultando em menor trauma pós-operatório.

Ainda existe dificuldade para padronizar o método, mas a ferramenta robótica nos permite aplicar os conceitos atuais de reconstrução da parede abdominal por via minimamante invasiva, que são: dissecção das referências anatômicas sem exposição ampla de pele e subcutâneo; posicionamento das telas nos compartimentos intermusculares, evitando contato delas com conteúdo intra-abdominal; separação de componentes e sutura das linhas de contenção da parede abdominal| ${ }^{15,16}$.

O fechamento da borda medial da aponeurose posterior dos músculos retos do abdomen parece natural, como se estivesse fechando a linha média com a pele aberta. Segue os princípios preconizados pela 


\section{escola francesa $a^{4,10,14,16}$.}

Também mostrou-se necessário o fechamento do tunel retromuscular, uma vez que dois pacientes tiveram compliações relacionadas ao não fechamento na altura da linha semilunar.

\section{CONCLUSÃO}

O procedimento robótico para reconstrução da linha média mostrou-se factível e esteticamente aceitável. Tem a vantagem de seguir os princípios tradicionais aventados pelos estudiosos da parede abdominal através de via minimamente invasiva.

\section{REFERÊNCIAS}

1. Burger JW, Luijendijk RW, Hop W, Halm JA, Verdaasdonk EG, Jeekel J. Long-term follow-up of a randomized controlled trial of suture versus mesh repair of incisional hernia. Ann Surg. 2004;240(4):57883; discussion 583-5.

2. Carbajo MA, Martin del Olmo JC, Blanco JI, de la Cuesta C, Toledano $\mathrm{M}$, Martin F, et al. Laparoscopic treatment vs open surgery in the solution of major incisional and abdominal wall hernias with mesh. Surg Endosc. 1999;13(3):250-2.

3. Carlson MA, Ludwig KA, Condon RE. Ventral hernia and other complications of 1,000 midline incisions. South Med J. 1995;88(4):450-3.

4. Chevrel JP, Flament JB. Les éventrations de la paroi abdominale. Rapport au 92ème Congrès Français de Chirurgie, A.F.C., Masson, Paris; 1990. (

5. Doherty GM. Diagnóstico $\mathrm{Y}$ tratamiento quirúrgicos. México: Manual Moderno; 2007.

6. Heniford BT, Park A, Ramshaw BJ, Voeller G. Laparoscopic repair of ventral hernias: nine years' experience with 850 consecutive hernias. Ann Surg. 2003;238(3):319-9; discussion 399-400.
7. Heniford BT, Park A, Ramshaw BJ, Voeller G. Laparoscopic ventral and incisional hernia repair in 407 patients. J Am Coll Surg. 2000;190(6):645-50.

8. Herszage L. Hernias ventrales. Cirurjano General. 2005;27(4):3127. Available from: http://www.medigraphic.com/pdfs/cirgen/cg2005/cg054k.pdf. Accessed in 2012 (Mar 14).

9. Hesselink VJ, Luijendik RW, de Wilt JH, Heide R, Jeekel J. An evaluation of risk factors in incisional hernia recurrence. Surg Gynecol Obstet. 1993;176(3):228-34.

10. Korenkov M, Paul A, Sauerland S, Neugebauer E, Arndt M, Chevrel JP, et al. Classification and surgical treatment of incisional hernia. Results of an experts' meeting. Langenbecks Arch Surg. 2001;386(1):65-73.

11. LeBlanc KA, Booth WV, Whitaker JM, Bellanger DE. Laparoscopic incisional and ventral herniorrhaphy in 100 patients. Am J Surg. 2000;180(3):193-7.

12. LeBlanc KA, Booth WV. Laparoscopic repair of incisional abdominal hernias using expanded polytetrafluorethylene: preliminary findings. Surg Laparosc Endosc. 1993;3(1):39-41.

13. Luijendijk RW, Hop WC, van den Tol MP, de Lange DC, Braaksma $\mathrm{MM}$, IJzermans JN, et al. A comparison of suture repair with mesh repair for incisional hernia. N Engl J Med. 2000;343(6):392-8.

14. Santora TA, Roslyn JJ. Incisional hernia. Surg Clin North Am. 1993;73(3):557-70.

15. Stoppa R, Moungar F, Verhaeghe P. Traitement chirurgical des éventrations médianes sus-ombilicales [Surgical treatment of supraumbilical eventrations]. J Chir (Paris). 1992:129(6-7):335-43.

16. Stoppa R, Henry X, Canarelli JP, Largueche S, Verhaeghe P, Abet $D$, et al. Les indications de méthodes opératoires sélectionnées dans le traitement des éventrations post-opératoires de la paroi abdominale antéro-latérale. Propositions fondées sur une série de 326 observations [Indications for selective operative procedures in the treatment of post-operative eventrations of the anterolateral abdominal wall (author's transl)]. Chirurgie 1979;105:276-86.

17. Toy FK, Balley RW, Carey S, Chappuis CW, Gagner M, Josephs LG, et al. Prospective, multicenter study of laparoscopic ventral hernioplasty. Preliminary results. Surg Endosc. 1998;12(7):955-9. 